\title{
KEEFEKTIFAN PROGRAM INDONESIA PINTAR DI MADRASAH KABUPATEN GORONTALO
}

\author{
Syafrin Ngiode ${ }^{1}$, Alfian Erwinsyah ${ }^{2}$ \\ IAIN Sultan Amai Gorontalo, Gorontalo, Indonesia \\ Email : syafrinngiode16@gmail.com ${ }^{1}$, alfianerwinsyah@gmail.com²
}

\begin{tabular}{l|c|r}
\multicolumn{3}{c}{ DOI: http:// doi.org/10.33650/al-tanzim.v4i1.987 } \\
\hline Received: Februari 2020 & Accepted: Maret 2020 & Published: Maret 2020 \\
\hline
\end{tabular}

\begin{abstract}
:
This study aims to determine the effectiveness of the Smart Indonesia Program (PIP) in madrasah, Gorontalo District, Gorontalo Province. This research uses mixed methods. Data collection techniques carried out through observation, interviews, questionnaires, and documentation. The data analysis technique is done in stages, starting from editing, coding tabulating, scoring to drawing conclusions. The results showed that: Input component score is 87 (effective), consisting of guidelines book, objectives, program objectives, PIP recipient requirements, student allocation, fund amount, determination of prospective students receiving assistance, submission of PIP recipients, PIP program funds distribution and withdrawal, realization of PIP disbursement and reporting, are considered effective, because their implementation refers to the technical guidelines for the implementation of the Smart Indonesia Program in madrasah. Output component score of 90 (effective). The indicators on the use of funds are considered effective, because students have used them well to meet their educational needs. The PIP recipient's liability indicator is in the effective category, because in PIP acceptance, madrasah students have an obligation to report the value of their semester results, PIP will be canceled if the requirements are not met.
\end{abstract}

Key words : Smart Indonesia Program (PIP), madrasah, evaluation

\begin{abstract}
Abstrak :
Penelitian ini bertujuan untuk mengetahui keefektifan Program Indonesia Pintar (PIP) di Madrasah Kabupaten Gorontalo, Provinsi Gorontalo. Penelitian ini menggunakan pendekatan campuran (mixed methods). Teknik pengumpulan data dilakukan melalui observasi, interview, angket/kuesioner, dan dokumentasi. Teknik analisis datanya dilakukan secara bertahap, yang dimulai dari editing, coding tabulating, skoring sampai pada penarikan kesimpulan. Hasil penelitian menunjukkan bahwa: Skor komponen input yaitu 87 (efektif), terdiri atas adanya buku pedoman/juknis pelaksanaan, tujuan, sasaran program, persyaratan penerima PIP, alokasi siswa, besaran dana, penentuan calon siswa penerima bantuan, pengajuan penerima PIP, penyaluran dan pengambilan dana Program PIP, realisasi pencairan dan pelaporan PIP, dinilai efektif, karena pelaksanaannya mengacu pada petunjuk teknis pelaksanaan Program Indonesia Pintar di madrasah. Skor komponen Output sebesar 90 (efektif). Pada indikator pemanfaatan dana dinilai efektif, karena sudah digunakan siswa dengan baik untuk memenuhi kebutuhan pendidikannya. Pada indikator kewajiban penerima PIP berada dalam kategori efektif, karena dalam penerimaan PIP, siswa madrasah mempunyai kewajiban untuk melaporkan nilai hasil semesternya, jika tidak dipenuhi, maka PIP akan dibatalkan.
\end{abstract}

Kata Kunci : Program Indonesia pintar, madrasah, evaluasi 


\section{PENDAHULUAN}

Salah satu komponen yang menjadi tolak ukur dari berkembangnya suatu negara adalah pendidikan (Rozi, 2019). Pendidikan memegang peran penting dalam pembentukan pribadi peserta didik (Wahid, 2018). Bahkan, pendidikan merupakan agen penting dalam membentuk pribadi bangsa (Arif \& Pratama, 2019). Begitu besar peran pendidikan sehingga perlu adanya solusi yang mampu menjawab tuntutan dan tantangan tersebut. Salah satu yang mendukung pelaksanaan pendidikan adalah pemberian beasiswa atau biaya penunjang pendidikan bagi siswa yang kurang mampu (Erwinsyah, 2017).

Berangkat dari pentingnya keberadaan lembaga pendidikan bagi keberhasilan pendidikan (Amin, 2018), maka sudah seharusnya pemerintah memberikan perhatian yang optimal kepada seluruh lembaga pendidikan yang ada, tanpa membedakan latar belakang dan status mereka (Kurniawan, 2017). Dalam Instruksi Presiden Nomor 7 Tahun 2014, mengamanatkan Program Indonesia Pintar (PIP) kepada Kementerian Pendidikan dan Kebudayaan untuk menyiapkan Kartu Indonesia Pintar (KIP) dan menyalurkan dana Program Indonesia Pintar (PIP) kepada siswa yang orang tuanya tidak mampu membiayai pendidikannya (Yusup, 2019).

Program Indonesia Pintar (PIP) melalui Kartu Indonesia Pintar ini, merupakan kelanjutan dari program Bantuan Siswa Miskin (BSM) yang mencakup siswa dari jenjang pendidikan SD/MI, SMP/MTs, SMA/SMK/MA, dan siswa/warga belajar di Pusat Kegiatan Belajar (PKBM)/ lembaga kursus dan pelatihan dari rumah tangga/ keluarga dengan status ekonomi terendah secara nasional .

Berdasarkan peraturan tersebut, dalam rangka pemerataan pendidikan (Idrus, 2012); (Hakim, 2016), khususnya dalam memberikan kesempatan kepada setiap anak yang berasal dari keluarga kurang mampu agar dapat tetap bersekolah, maka peningkatan akses dan mutu pendidikan kepada masyarakat terus dilakukan oleh pemerintah (Syamsuddin, 2017), sebagai upaya meningkatkan kualitas sumber daya manusia yang dapat membangun dan memajukan bangsa (Rachmawati, 2008); (Kisbiyanto, 2014); (Jaya, 2017), agar tercapai masyarakat yang berilmu, cerdas dan berkarakter (Lickona, 1991); (Abu, 2015); (Komalasari, 2018), melalui berbagai program pembangunan di bidang pembiayaan pendidikan, sebagai investasi besar dalam mewujudkan pembangunan yang berkelanjutan (William, 2017).

Pemerintah memperluas cakupan pemberian bantuan tunai pendidikan melalui Program Indonesia Pintar untuk peningkatan kesejahteraan masyarakat kurang mampu, serta mendorong kontinuitas pendidikan anak dari keluarga kurang mampu (Ahmad, 2018). Dengan cakupan yang lebih luas, pemerintah berusaha menjangkau anak putus sekolah dari keluarga kurang mampu, agar mau kembali melanjutkan pendidikannya. Permendikbud No.12 Tahun 2015 tentang Program Indonesia Pintar (PIP) menyampaikan secara tertulis bahwa; Program Indonesia Pintar merupakan bantuan tunai pendidikan yang ditujukan bagi anak usia sekolah (6-21 tahun) (Kemendikbud, 2018).

Program Indonesia Pintar merupakan pemberian bantuan tunai dari pemerintah kepada anak usia sekolah dari keluarga kurang mampu, yang 
ditandai dengan pemberian Kartu Indonesia Pintar (KIP) (Hasan, 2017). Kartu Indonesia Pintar diberikan kepada anak usia sekolah dari keluarga yang memiliki Kartu Keluarga Sejahtera (KKS) dengan tujuan menjamin seluruh anak usia sekolah dapat menempuh pendidikan dari Sekolah Dasar, Sekolah Menengah Pertama dan Sekolah Menengah Atas/Kejuruan.

Keefektifan dari bantuan pemerintah yang berupa Program Indonesia Pintar tentunya menarik perhatian para akademisi untuk melakukan riset tentang alokasi dana pemerintah tersebut. Penelitian yang dilakukan oleh Rohaeni (2018) menunjukan bahwa; dana PIP yang diberikan kepada peserta didik di SMP Negeri 1 Manonjaya dan SMP Negeri 2 Cineam Tasikmalaya, dikelola dengan baik sesuai dengan juknis yang ada, sehingga kendala biaya pendidikan dari peserta didik dapat teratasi. Di samping itu, terdapat pula penyahgunaan dari Program Indonesia Pintar, sebagaimana disampaikan oleh Retnaningsih (2017), yang menyatakan bahwa bantuan PIP di Kota Kupang dan Kota Palembang kurang optimal, karena adanya intervensi elit politik lokal dengan cara memaksanakn nama-nama siswa yang harus diberi bantuan.

Begitu juga dengan penelitian Hasan (2017), yang menunjukkan bahwa; penggunaan dana bantuan pendidikan dari pemerintah, baik melalui Program Indonesia Pintar maupun Program Keluarga Harapan di SDN Jogosatru Sidoarjo kurang efektif, tidak tepat sasaran dan disalahgunakan oleh beberapa oknum. Yusuf (2019) juga menyampaikan bahwa terdapat kesenjangan antara tujuan pelaksanaan PIP di SMP Negeri 7 Salatiga dengan juknis pelaksanaan PIP dari pemerintah, yang ditinjau dalam aspek desain, proses, produk dan kemanfaatannya.

Demikian halnya dengan keefektifan pelaksanaan program PIP di Madrasah di kecamatan Tabongo Kabupaten Gorontalo sebagai situs penelitian ini, yaitu Madrasah Tsanawiyah Negeri 2 dan Madrasah Aliyah Negeri 2 Kabupaten Gorontalo. Program Indonesia Pintar peruntukannya menjadi urgen bagi siswa. Melalui kordinasi yang berkesinambungan antara lembaga terkait, diharapkan program pemberian PIP melalui KIP dalam bentuk kartu ATM dapat berjalan efektif dalam mencapai tujuan pelaksanaan program ini.

Mengingat banyaknya permasalahan yang harus dievaluasi dalam kegiatan program PIP, maka fokus penelitian ini adalah ketercapaian tujuan program PIP dalam kegiatan yang dianggap penting, dengan berpedoman pada teori goal oriented model Ralph Winfred Tyler, yang dibuat untuk mengetahui tujuan program yang telah dicapai (Läänemets \& KalameesRuubel, 2013). Tyler menggunakan kesenjangan antara apa yang diharapkan dan apa yang berhasil diamati, untuk memberikan masukan terhadap kekurangan dari suatu program (Tayibnapis, 2008).

Penelitian ini diarahkan untuk memahami tentang keefektifan program PIP di Madrasah Tsanawiyah Negeri 2 dan Madrasah Aliyah Negeri 2 Kabupaten Gorontalo yang berorientasi pada ketercapaian tujuan. Secara umum masalah penelitian yaitu; Bagaimana keefektifan program PIP melalui KIP yang berorientasi pada ketercapaian tujuan (Goal-Oriented) dari aspek input, output di Madrasah Kabupaten Gorontalo ?. 


\section{METODE PENELITIAN}

Penelitian ini menggunakan pendekatan campuran (mixed methods), di mana pendekatan ini mengkombinasikan atau mengasosiasikan bentuk kualitatif dan bentuk kuantitatif dalam menghasilkan temuan penelitian, yaitu tentang keefektifan Program Indonesia Pintar di madrasah Kabupaten Gorontalo. Situs penelitian ini di Madrasah Tsanawiyah Negeri 2 dan Madrasah Aliyah Negeri 2 Kabupaten Gorontalo.

Teknik pengumpulan data dilakukan melalui observasi dan interview terhadap pelaksanaan Program Indonesia Pintar di madrasah Kabupaten Gorontalo, penyebaran angket/kuesioner kepada penerima PIP, dan dokumentasi terhadap aktivitas pelaksanaan Program Indonesia Pintar di madrasah Kabupaten Gorontalo. Tekhnik analisis datanya dilakukan secara bertahap, yang dimulai dari editing, coding tabulating, skoring sampai pada penarikan kesimpulan.

\section{HASIL DAN PEMBAHASAN}

Keefektifan Program PIP di Madrasah Kabupaten Gorontalo Ditinjau dari Aspek Masukan Program (Input)

Untuk memberikan gambaran yang jelas tentang hasil analisis data yang diperoleh dari hasil wawancara dalam pelaksanaan program Program Indonesia Pintar (PIP) di Madrasah Tsanawiyah Negeri 2 dan Madrasah Aliyah Negeri 2 Kabupaten Gorontalo, berikut ini dipaparkan skor-skor aspek komponen input yang diperoleh melalui tabel berikut;

Tabel 1 :

Skor Terhadap Pelaksanaan Program PIP di Madrasah Ditinjau dari Aspek Masukan (Input)

\begin{tabular}{llcl}
\hline No & \multicolumn{1}{c}{ Indikator } & $\begin{array}{c}\text { Rata-Rata } \\
\text { Skor }\end{array}$ & Kategori \\
\hline 1 & Buku pedoman/juknis pelaksanaan PIP & 95 & Sangat efektif \\
\hline 2 & Tujuan Program & 90 & Efektif \\
\hline 3 & Sasaran Program & 85 & Efektif \\
\hline 4 & Persyaratan siswa penerima PIP & 90 & Efektif \\
\hline 5 & Alokasi siswa dan besaran dana PIP & 90 & Efektif \\
\hline 6 & Penentuan calon siswa penerima PIP & 85 & Efektif \\
\hline 7 & Pengajuan siswa penerima PIP & 85 & Efektif \\
\hline 8 & Penyaluran dan pengambilan dana PIP & 80 & Efektif \\
\hline 9 & Realisasi pencairan & 80 & Efektif \\
\hline 10 & Pelaporan & 90 & Efektif \\
\hline \multirow{2}{*}{ Jumlah Skor } & $\mathbf{8 7 0}$ & \\
\hline
\end{tabular}


Pada indikator buku pedoman/juknis pelaksanaan program PIP di Madrasah Tsanawiyah Negeri 2 dan Madrasah Aliyah Negeri 2 Kabupaten Gorontalo dinilai sangat efektif. Karena dalam program PIP terdapat buku petunjuk teknis pelaksanaan Program Indonesia Pintar (PIP) di Madrasah, sehingga rumusan tujuan program berpedoman pada buku petunjuk/juknis program PIP.

Selanjutnya tingkat kebersamaan penyusunan tujuan program PIP di madrasah dengan warga madrasah berjalan dengan efektif. Tanpa kerja sama yang baik, tentunya tujuan program PIP tidak akan berjalan dengan efektif. Demikian halnya dengan sasaran program PIP di Madrasah Tsanawiyah Negeri 2 dan Madrasah Aliyah Negeri 2 Kabupaten Gorontalo dalam kategori efektif, karena penentuan siswa penerima dana PIP berdasarkan verifikasi oleh tim manajemen PIP madrasah, dan selalu diprioritaskan bagi siswa miskin.

Pada indikator persyaratan siswa penerima PIP, juga berada pada kategori efektif, karena dalam program ini siswa penerima PIP mempunyai persyaratan tersendiri yang sudah ditetapkan dalam juknis yakni; siswa penerima PIP harus berasal dari keluarga kurang mampu secara ekonomi, siswa miskin yang terancam putus madrasah, dan diusulkan oleh madrasah bersangkutan, dan disetujui oleh Kemenag kabupaten Gorontalo sebagai calon penerima PIP.

Persyaratan lain yang diterapkan pada siswa penerima PIP yaitu siswa harus punya Kartu Perlindungan Madrasah (KPS), siswa memiliki surat keterangan ekonomi lemah dari kelurahan, dan siswa sudah pegang kartu BPJS. Semua persyaratan ini telah disetujui dan diterapkan oleh siswa penerima PIP di Madrasah Tsanawiyah Negeri 2 dan Madrasah Aliyah Negeri 2 Kabupaten Gorontalo, sehingga dalam kategori efektif.

Berdasarkan hasil wawancara dengan Ibu Darwati Nalole (2019) sebagai pengelola PIP di MTsN 2 Kabupaten Gorontalo bahwa pada tahun 2018/2019 siswa yang diusulkan menerima PIP berjumlah 350 orang dan yang menerima hanya 71 orang. Bantuan ini disalurkan secara bertahap. Jadi siswa yang belum mendapatkan PIP pada tahap pertama, bisa diusulkan kembali pada tahap berikutnya.

Implementasi program yang didasarkan pada juknis, tujuan, sasaran, persyaratan siswa penerima PIP akan membuka peluang besar bagi keberhasilan program PIP di madrasah, yaitu membantu pemerataan masyarakat dalam mengakses pendidikan, sehingga peserta didik yang berasal dari keluarga yang kurang mampu dapat mengakses pendidikan. akses pendidikan harus terus ditingkatkan agar semua kalangan dapat menikmati pendidikan menuju masyarakat yang sejahtera (Yusup, 2019).

Pada indikator alokasi siswa dan besaran dana PIP berada dalam kategori efektif. Biaya satuan Rp 1.000 .000 per siswa per tahun atau Rp 500.000 per siswa per 6 bulan/semester. Jadi dapat dipahami bahwa alokasi siswa dan besaran dana PIP di Madrasah Tsanawiyah Negeri 2 dan Madrasah Aliyah Negeri 2 Kabupaten Gorontalo dalam kategori efektif. Hal ini dapat dilihat dari besar dana PIP yang dimanfaatkan dengan sebaik-baiknya oleh siswa untuk 
memenuhi kebutuhan pendidikannya, sesuai dengan tujuan yang ditetapkan dalam juknis yang ada.

Dengan adanya dana bantuan Kartu Indonesia Pintar (KIP) diharapkan untuk bisa mensejahterakan siswa agar dapat berkembang seperti halnya dalam kekurangan uang saku maka siswa dapat terpenuhi uang sakunya dan kekurangan pada alat sekolah juga dapat terpenuhi (Rohaeni, 2018). Dana PIP harus dimanfaatkan guna menunjang kelancaran peserta didik bersekolah, bukan untuk hal lainnya (Zamjani, 2018).

Selanjutnya pada indikator penyaluran dan pengambilan dana PIP juga di nilai dalam kategori efektif. Karena dari hasil wawancara dengan Romi Bau (Ahmad, 2018), selaku Kepala madrasah di MAN 2 Kabupaten Gorontalo menyatakan bahwa; penyaluran dan pengambilan dana PIP dalam hal ini, madrasah tidak menerimakan PIP, tetapi bantuan ini langsung di salurkan oleh penyalur melalui bank. Bantuan ini diterima oleh siswa melalui kartu rekening mereka, dan sudah tidak ada potongan apa-apa. Bantuan ini digunakan siswa untuk memenuhi kebutuhan siswa di madrasah terutama untuk perlengkapan madrasah dan transportasi. Tugas madrasah di sini mendata nama-nama siswa dan mengusulkannya kepada Kementerian Agama Kabupaten, untuk selanjutnya diverifikasi ke Bidang Pendidikan Madrasah, untuk dipertimbangkan siapa saja siswa yang wajib menerima bantuan PIP, yang selanjutnya data-data siswa penerima PIP dilaporkan kembali kepada pihak madrasah.

Pada indikator realisasi pencairan dana PIP berada dalam kategori efektif, karena berdasarkan hasil observasi di Madrasah Tsanawiyah Negeri 2 dan Madrasah Aliyah Negeri 2 Kabupaten Gorontalo, didapatkan bahwa; pencairan dana PIP langsung diterima oleh siswa di Bank dan sudah tidak ada potongan apa-apa. Dengan besaran dana yang diterima siswa Rp 1.000.000 per siswa per tahun. Jadi setiap 6 bulan siswa menerima dana sebesar Rp 500.000/semester yang dimanfaatkan siswa untuk kebutuhan pendidikannya. Sebelum menerima PIP siswa harus membuka rekening terlebih dahulu di Bank untuk mendapatkan KIP berupa kartu ATM, agar pencairannya langsung ke rekening siswa.

Melalui Bantuan berupa uang tunai yang dicairkan melalui virtual account dari Bank milik Negara (Retnaningsih, 2017), maka banyak kemudahan yang didapatkan oleh siswa dalam penyaluran PIP ini. Implikasi dari bantuan tersebut, tentunya sangat memudahkan siswa dalam menjalankan proses pendidikannya di Madrasah khususnya bagi siswa. Sehingga orang tua siswa yang ekonominya lemah, tidak kesulitan lagi dalam menyekolahkan anakanaknya.

Pada indikator pelaporan dana PIP dinilai dalam kategori efektif, karena pihak Madrasah Tsanawiyah Negeri 2 dan Madrasah Aliyah Negeri 2 Kabupaten Gorontalo tidak bersusah payah lagi dalam menerimakan dana PIP dan membuat rincian aggarannya, tetapi sudah diterima oleh siswa penerima PIP melalui rekening mereka. Pelaporan dana PIP yang dimaksud dalam petunjuk teknis ini adalah berupa bukti transfer penyaluran dana yang diterbitkan oleh lembaga penyalur ke nomor rekening atas nama siswa 
penerima bantuan, yang sesuai dengan Surat Keputusan Bidang Pendidikan Madrasah.

Pihak madrasah di sini menerima langsung laporan nama-nama siswa penerima PIP dari lembaga penyalur dan siswa memperlihatkan bukti transfer penyaluran dana PIP. Tugas kepala madrasah membina dan mengawasi program PIP agar berjalan efektif sesuai dengan juknis yang ada. Selain itu, guru yang ditugaskan sebagai pengelola PIP, harus mendata nama-nama siswa sejak penerimaan siswa baru dengan memenuhi persyaratan yang diajukan, sesuai dengan juknis yang ada.

Berdasarkan skor-skor komponen input dari program PIP di Madrasah Tsanawiyah Negeri 2 dan Madrasah Aliyah Negeri 2 Kabupaten Gorontalo tersebut, diperoleh skor keseluruhan komponen input yaitu 87. Skor ini menunjukkan kualifikasi komponen input dari program PIP di Madrasah Tsanawiyah Negeri 2 dan Madrasah Aliyah Negeri 2 Kabupaten Gorontalo tahun pelajaran 2018/2019 termasuk kategori efektif.

Berdasarkan 10 indikator yang telah dideskripsikan pada tabel di atas, hasil temuan secara keseluruhan berada pada kategori efektif, yaitu adanya buku pedoman/juknis pelaksanaan program, tujuan program, sasaran program, persyaratan siswa penerima PIP, alokasi siswa dan besaran dana program PIP, penetuan calon siswa penerima bantuan, pengajuan siswa penerima PIP, penyaluran dan pengambilan dana Program PIP, realisasi pencairan PIP dan pelaporan. Dengan demikian dapat ketahui bahwa keefektifan program Program Indonesia Pintar di Madrasah Tsanawiyah Negeri 2 dan Madrasah Aliyah Negeri 2 Kabupaten Gorontalo dinilai dari aspek masukan (input) berada dalam kategori efektif dengan mengacu pada peraturan yang ditetapkan dalam juknis yang ada.

Berdasarkan hasil wawancara yang dilakukan peneliti tentang komponen input dari program PIP di Madrasah Tsanawiyah Negeri 2 dan Madrasah Aliyah Negeri 2 Kabupaten Gorontalo tahun pelajaran 2018/2019, didapatkan bahwa terjadi peningkatan pada komponen input yaitu; tujuan sudah dirumuskan secara jelas mengacu pada buku pedoman/petunjuk dan juknis yang ada, tujuan dan sasaran program jelas. Meskipun dalam penjadwalan pencairan dana kurang tepat waktu, tapi perlu ditingkatkan ketepatannya.

Namun, setidaknya dengan adanya program PIP bisa membantu biaya madrasah anak dari kalangan ekonomi bawah dan PIP juga menyediakan komponen-komponen untuk keperluan pembelajaran, yang terpenting dengan program PIP anak dari keluarga tidak mampu dapat terbantu (Saryono, 2018); (Yusup, 2019); (Retnaningsih, 2017). Melalui program ini, orang tua siswa tidak bersusah payah lagi dalam memikirkan biaya untuk keperluan pendidikan anaknya di Madrasah.

\section{Keefektifan Program PIP di Madrasah Kabupaten Gorontalo ditinjau dari Aspek Komponen Keluaran (Output)}

Untuk mengevaluasi pelaksanaan program PIP di Madrasah Tsanawiyah Negeri 2 dan Madrasah Aliyah Negeri 2 Kabupaten Gorontalo ditinjau dari aspek komponen keluaran (output) program, dinilai berdasarkan 2 (dua) 
indikator yaitu; pemanfaatan dana PIP dan kewajiban siswa penerima PIP. Kedua indikator ini dinilai sangat penting dalam pelaksanaan program PIP, karena akan mempengaruhi tingkat ketercapian tujuan. Dalam tabel berikut akan diuraikan skor terhadap pelaksanaan program PIP di Madrasah Tsanawiyah Negeri 2 dan Madrasah Aliyah Negeri 2 Kabupaten Gorontalo;

Tabel 2 :

Skor Terhadap Pelaksanaan Program PIP di Madrasah Ditinjau Aspek Komponen Keluaran (Output)

\begin{tabular}{clcc}
\hline No & \multicolumn{1}{c}{ Indikator } & $\begin{array}{c}\text { Rata-Rata } \\
\text { Skor }\end{array}$ & Kategori \\
\hline 1 & Pemanfaatan Dana & 90 & Efektif \\
\hline 2 & Kewajiban siswa penerima PIP & 90 & Efektif \\
\hline 3 & Sasaran Program & 85 & Efektif \\
\hline & Jumlah Skor & $\mathbf{1 8 0}$ & \\
\hline & Rata-Rata Skor Total & $\mathbf{9 0}$ & Efektif
\end{tabular}

Berdasarkan informasi dari para pengelola PIP, dapat diketahui bahwa; pelaksanaan program PIP di Madrasah Tsanawiyah Negeri 2 dan Madrasah Aliyah Negeri 2 Kabupaten Gorontalo ditinjau dari pemanfaatan dana PIP tergolong efektif. Hal ini disebabkan karena semua indikator yang diteliti berada pada kategori efektif. Pada indikator pemanfaatan dana PIP dinilai efektif, karena hal ini dapat dilihat dari pemanfaatan dana PIP di Madrasah Tsanawiyah Negeri 2 dan Madrasah Aliyah Negeri 2 Kabupaten Gorontalo yang sudah digunakan siswa dengan sebaik-baiknya untuk memenuhi kebutuhan pendidikannya. Program PIP dimanfaatkan oleh siswa untuk membiayai keperluan sehari-hari siswa untuk menunjang pendidikannya.

Dari hasil observasi di Madrasah Kecamatan Tabongo, bahwa pemanfaatan dana PIP digunakan untuk; Pengadaan bahan, alat tulis, buku, Pengadaan seragam madrasah, tas, biaya transport pulang dan pergi ke madrasah, uang saku siswa di madrasah, dan biaya les. Dengan program PIP ini, siswa sangat terbantu untuk memenuhi kebutuhan pendidikannya. Jadi orang tua siswa yang ekonominya lemah tidak kesulitan lagi dalam menyekolahkan anaknya di Madrasah.

Pada indikator kewajiban penerima PIP berada dalam kategori efektif, karena dalam penerimaan PIP, siswa mempunyai kewajiban tertentu yang harus dipenuhi selama menerima bantuan tersebut. Setiap semester siswa harus melaporkan nilai hasil semesternya, karena jika tidak dipenuhi, maka Kepala Madrasah bersama dewan guru dan komite madrasah bertanggung jawab dan berwenang untuk membatalkan PIP.

Siswa penerima PIP di Madrasah harus dapat melaksanakan kewajibannya dengan baik. Adapun kewajiban siswa penerima PIP yaitu: Belajar dengan giat dan fokus, menjunjung kedisiplinan dalam pelaksanaan 
kewajiban belajar di madrasah, dan memperlihatkan akhlak terpuji dan menghindari perbuatan yang tidak terpuji. Serta memakai bantuan dana PIP sesuai dengan ketentuan pemanfaatan dana yang ditetapkan dalam juknis yang ada (Kemendikbud, 2018).

Sebuah program dapat dikatakan berhasil dan sukses jika memenuhi kriteria keberhasilan yang ditetapkan, baik oleh lembaga ataupun pemerintah. Karena kriteria merupakan hal yang paling penting kedudukannya dan harus disiapkan sebelum peneliti bertolak mengumpulkan data di lapangan. Adapun kriteria keberhasilan program berdasarkan kriteria-kriteria yang dievaluasi tersebut dapat dijabarkan sebagai berikut; Program Indonesia Pintar sedianya dilaksanakan agar kebutuhan siswa yang kurang mampu bisa terpenuhi dan tidak mengalami hambatan, sehingga siswa termotivasi lagi dalam proses pembelajaran.

Berangkat dari hal tersebut di atas, dapat diketahui bahwa Program Indonesia Pintar (PIP) di Madrasah Tsanawiyah Negeri 2 dan Madrasah Aliyah Negeri 2 Kabupaten Gorontalo berjalan lancar, efektif dan efisien serta memberikan manfaat yang sangat besar kepada peserta didik pada kedua madrasah tersebut.

\section{KESIMPULAN}

Berdasarkan analisis data terhadap keefektifan Program Indonesia Pintar (PIP) di Madrasah Tsanawiyah Negeri 2 dan Madrasah Aliyah Negeri 2 Kabupaten Gorontalo tahun pelajaran 2018/2019 dinilai dalam kategori efektif dan pelaksanaanya sudah sesuai dengan tujuan yang ditetapkan dalam juknis yang ada. Penerima bantuan Program Indonesia Pintar (PIP) sudah tepat sasaran, yaitu siswa dari keluarga miskin atau kurang mampu. Pemanfaatan dana yang diperoleh dari Program Indonesia Pintar (PIP) melalui Kartu Indonesia Pintar (KIP) sudah sesuai dengan juknis dari pemerintah, yaitu diperuntukkan untuk keperluan perlengkapan sekolah seperti pembelian buku, ATK, , seragam, transportasi siswa ke sekolah, uang saku, dan biaya kursus/les tambahan.

Hal yang menjadi catatan penting dalam pelaksanaan Program Indonesia Pintar di di Madrasah Tsanawiyah Negeri 2 dan Madrasah Aliyah Negeri 2 Kabupaten Gorontalo, yaitu pada waktu pencairan dana yang selalu tidak sesuai dengan waktu yang ditentukan, sehingga siswa bersama orang tuanya harus mengorbankan waktu untuk bolak-balik ke Bank yang ditunjuk. Selain itu, Program Indonesia Pintar harus tepat sasaran. Para pengelola harus mengawal dan melaksanakan program dengan sungguh-sungguh sesuai dengan pedoman dan juknis yang berlaku, agar supaya tujuan dari program ini dapat tercapai secara optimal. 


\section{DAFTAR PUSTAKA}

Abu, L., Mokhtar, M., Hassan, Z., Zakiah Darmanita Suhan, S., Abu Student, L., Mokhtar Senior, M. (2015). How to Develop Character Education of Madrassa Students in Indonesia. Journal of Education and Learning, 9(1), 79-86.

Ahmad. (2018). Kinerja Program Indonesia Pintar melalui Kartu Indonesia Pintar (Survei Pada 6 Provinsi di Indonesia). Journal of Economics and Management, 19(1), 523-542.

Amin, N., Siswanto, F., \& Hakim, L. (2018). Membangun Budaya Mutu yang Unggul dalam Organisasi Lembaga Pendidikan Islam. Al-Tanzim: Jurnal Manajemen Pendidikan Islam, 2(1), 80-93.

Arif, D., \& Pratama, N. (2019). Tantangan Karakter di Era Revolusi Industri dalam Membentuk Kepribadian Muslim. Al-Tanzim: Jurnal Manajemen Pendidikan Islam, 3(1), 198-226.

Arroyo, G. C., \& Garduño, J. M. G. (2004). Tyler's Curriculum Rationale and the Reconceptualists. Interview with Ralph W. Tyler (1902-1994). Revista Electrónica de Investigación Educativa, 6(2), 1-18.

Bau, R. (2019). Interview. MAN 2 Gorontalo, Gorontalo.

Erwinsyah, A. (2017). Manajemen Pembelajaran dalam Kaitannya dengan Peningkatan Kualitas Guru. Tadbir: Jurnal Manajemen Pendidikan Islam, 5(1), 69-84.

Hakim, L. (2016). Pemerataan Akses Pendidikan bagi Rakyat sesuai dengan Amanat Undang-Undang Nomor 20 Tahun 2003 tentang Sistem Pendidikan Nasional. Jurnal Edutech, 2(1), 53-64.

Hasan, N. F. (2017). Efektivitas Penggunaan Dana Bantuan Pendidikan (Studi Kasus pada Siswa Peserta PIP dari Keluarga Peserta PKH di SDN Jogosatru Sidoarjo). Modeling: Jurnal Program Studi PGMI, 4(1), 1-18.

Idrus, M. (2012). Mutu Pendidikan dan Pemerataan Pendidikan di Daerah. Psikopedagogia, 1(2), 1-10.

Jaya, E. (2017). Manajemen Sumber Daya Manusia Pendidikan SMART Ekselensia Indonesia. Jurnal Pendidikan Dompet Dhuafa, 7(2), 1-8.

Kemendikbud. (2018). Kajian Program Indonesia Pintar (PIP): Strategi Penjangkauan Anak Tidak Sekolah (ATS) untuk Mengikuti Pendidikan melalui Program Indonesia Pintar (PIP). Jakarta: Pusat Penelitian Kebijakan Pendidikan dan Kebudayaan.

Kisbiyanto. (2014). Manajemen Kebijakan Sumber Daya Manusia Pendidikan : Studi Kasus di STAIN Kudus. Edukasia: Jurnal Penelitian Pendidikan Islam, 9(1), 129-146.

Komalasari, K., \& Saripudin, D. (2018). The Influence of Living Values Education-Based Civic Education Textbook on Student's Character Formation. International Journal of Instruction, 11(1), 395-410.

Kurniawan, S. (2017). Pengembangan Manajemen Mutu Pendidikan Islam Di Madrasah. Al-Tanzim: Jurnal Manajemen Pendidikan Islam, 1(2), 25-36.

Lickona, T. (1991). Educating for Character: How Our School Can Teach Respect and Responsibility. New York: Bantam Books.

Nalole, D. (2019). Interview. MTsN 2 Gorontalo, Gorontalo. 
Rachmawati, I. K. (2008). Manajemen Sumber Daya Manusia. Yogyakarta: Andi.

Retnaningsih, H. (2017). Program Indonesia Pintar: Implementasi Kebijakan Jaminan Sosial Bidang Pendidikan (Studi di Kota Kupang, Provinsi Nusa Tenggara Timur dan Kota Palembang, Provinsi Sumatera Selatan). Jurnal Aspirasi, 8(2), 161-177.

Rohaeni, N. E., \& Saryono, O. (2018). Implementasi Kebijakan Program Indonesia Pintar (PIP) Melalui Kartu Indonesia Pintar (KIP) dalam Upaya Pemerataan Pendidikan. Journal of Education Management and Administration Review, 2(1), 1-12.

Rozi, S. (2019). Pendidikan Moderasi Islam KH. Asep Saifuddin Chalim; Mencegah Radikalisme Agama dan Mewujudkan Masyarakat Madani Indonesia. Tarbiya Islamia: Jurnal Pendidikan dan Keislaman, 8(1), 26-43.

Syamsuddin. (2017). Penerapan Fungsi-Fungsi Manajemen dalam Meningkatkan Mutu Pendidikan. Jurnal Idaarah, 1(1), 60-73.

Tayibnapis, F. Y. (2008). Evaluasi Program dan Instrumen Evaluasi. Jakarta: Rineka Cipta.

Läänemets, U., \& Kalamees-Ruubel, K. (2013). The Taba-Tyler Rationales. Journal of the American Association for the Advancement of Curriculum Studies, 9, 1-12.

Wahid, A. H., Muali, C., \& Rafikah, K. (2018). Pengembangan Karakter Guru dalam Menghadapi Demoralisasi Siswa Perspektif Teori Dramaturgi. Jurnal Mudarrisuna, 8(1), 102-126.

William, N. D. (2017). Pengantar Analisis Kebijakan Publik. Yogyakarta: Gajah Mada University Press.

Yusup, W. B., Ismanto, B., \& Wasitohadi, W. (2019). Evaluasi Program Indonesia Pintar dalam Peningkatan Akses Pendidikan di Sekolah Menengah Pertama. Kelola: Jurnal Manajemen Pendidikan, 6(1), 44-53.

Zamjani, I. (2018). Pelaksanaan Program Indonesia Pintar Bagi Penerima Kartu Indonesia Pintar Reguler: Studi di Empat Daerah Kunjungan Kerja Presiden Tahun 2017 the Implementation of Smart Indonesia Program for the Recipients of Conventional Smart Indonesia Card: The Study. Jurnal Penelitian Kebijakan Pendidikan, 11(2), 64-82. 